[Deutsche Entomologische Zeitschrift XXVIII. 1884. Heft I.]

\title{
Beitrag zur Chrysomeliden-Fauna von Amasia
}

\author{
mitgetheilt von \\ J. W e i s e.
}

Die nachstehend verzeichneten Chrysomeliden wurden von Hrn. Funcke bei Amasia gesammelt und mir von Hrn. Möhring in Dresden, der dieselben erworben hat, zur Bestimmung übersandt. Ibre Aufzählung ist vielleicht deshalb nicht ganz ohne Interesse, weil dadurch die Kenntnifs vom Verbreitungsbezirke vieler, auch in Europa einheimischer Arten, erweitert wird.

Labidostomis asiatica Fald, propinqua Fald. und rufa Waltl zahlreich, maculipennis Lef, decipiens Fald. und brevipennis Fald. selten. Lachnaea sexpunctata var. pontica. Clytra elata var. aleppensis Redtb. Gynandrophthalma biornata Lef., limbata Stev. und graeca Lef. Cryptocephalus Prusias Suffr., Möhringi m., globicollis? Suffr., concolor Suffr. und ocellatus Drap., Pachybrachys tesselatus Ol., Pseudocolaspis graeca Lef., Colaphus sophiae Schall., Timarcha venosula Weise, Entomoscelis adonidis Pall., Chrysomela orientalis Ol., gypsophilae Küst., sculptipennis Fald., alternata Suffr., didymata Scriba und menthastri Suffr., Phytodecta fornicata Brüggem., Phyllodecta vulgatissima L., Melasoma populi L., Phyllobrotica elegans Kraatz, Galerucella subcoerulescens m., Psylliodes chalcomera Ill., Cassida liriophora Kirb. und brevis $\mathrm{m}$. An Coccinelliden fanden sich Coccinella lyncea var. asiatica, 14-pustulata L. und 7-punctata L., Adonia variegata Goez., Halyzia 12-guttata Poda und 22-guttata L., Subcoccinella 24-punctata L.

1. Lachnaea sexpunctata var. pontica. 2 t, die mit der in Oesterreich vorkommenden Normalform übereinstimmen, nur ist die Punktirung der Fld. stärker und der schwarze Punkt 3 der Fld. ist so weit nach hinten gerückt, dafs die gerade Linie, welche die Punkte 2 beider Decken verbindet, durch die Mitte der Punkte 3 geht. Aehnliche Stücke sind mir aus Europa nicht bekannt.

2. Gynandrophthalma biornata Lef. (Ann. Fr. 1872. 322): oblongo-elongata, obscure viridi-aurata, antennis nigro-aeneis, clypeo minus profunde emarginato, fronte inter oculos transversim impresso parce punctato, prothorace minus crebre, subtiliter elytrisque 
creberrime rugoso-punctatis, his macula apicali aurantiaca. - Long. $5-6$ mill.

Körperform von viridana Lac., in der Bildung des Kopfschildes und der Färbung mehr mit amabilis übereinstimmend, von dieser jedoch durch einfarbige Fühler und den rothen Spitzenfleck der Fld. verschieden, welcher nicht bis zum Hinterrande reicht, sondern dort von einem schmalen grünen Randsaume begrenzt wird. Aufserdem ist die Punktirung des Kopfes und Halsschildes weitläufiger und feiner, die der Fld. bedeutend stärker, dichter und zu scharfen Querrunzeln vereint; die Farbe viel dunkler, mehr bläulich-goldgrün, weniger glänzend. Lefèvre's kurze Beschreibung veranlalste mich, hier eine vollständigere zu geben. 3 Männchen.

3. Cryptocephalus Prusias Suffr. Ich wollte hier nur darauf hinweisen, dafs die Unterschiede, die Marseul in der Tabelle seiner Cryptocephales p. 56 anführt, so falsch sind, dafs sich die Art darnach nicht bestimmen läfst, denn das Halssch. ist nicht rugueusement ponctué, avec 2 petits points ronds et la bande latérale entière jaune. Die Art ähnelt tricolor Rossi aufserordentlich, aber die Seiten des Halsch. sind vorn weniger zusammengedrückt, der Seitenrand, besonders beim $\widetilde{\jmath}$, daher bis vorn sichtbar, das Halsch. ist feiner und seichter punktirt, stärker, lackartig glänzend, die beiden weifsen Seitenmakeln sind beim $\widehat{\sigma}$ schmal, beim $ᄋ$ breit oder oft vollständig zu einer Längsbinde vereint, die beiden weifsen Flecke vor dem Hinterrande klein, ziemlich rund $\left(\sigma^{\top}\right)$ oder grofs, schräg, elliptisch (ㅇ). Ein von Suffrian nicht erwähntes, sehr in die Augen fallendes Merkmal besteht darin, dafs der schwarze Fleck 3 jeder Fld. bei der vorliegenden Art rund ist.

4. Cryptocephalus (Proctophysus) Möhringi: Pilosus, coeruleo-viridis, antennis nigris, basi flavo-testaceis, facie, macula alba infra antennas notata, tuberculis 2 instructa, fronte subconvexa, vage canaliculata, lineolis 2 ocularibus flavis, thorace parce punctato nitido, angulis posticis subacutis, elytris crebre transversim rugulosopunctatis. - Long. 5-6 mill.

Mas.: Omnino ut in Cr. Schäfferi, sed antennis longioribus.

Fem.: Omnino ut in Cr. Schäfferi, sed emarginatura pygidii angusta, profunda.

Die Unterschiede von dem sehr ähnlichen $C r$. Schäfferi sind folgende: Die Farbe ist stärker grün, das Halssch. nach vorn gewölbter, meist feiner punktirt und glänzender, die Hinterecken sind länger ausgezogen und spitzer; die Fld. vorn stärker punktirt und kräftiger quer gerunzelt, auf dem Abfalle zur Spitze dagegen 
bedeutend feiner und sparsamer punktirt, die gelbe Linie in der Ausrandung der Augen ist stets deutlich. Das $\sigma^{\top}$ hat längere Fühler, deren 6 erste Glieder merklich schmaler sind; dem Penis fehlt auf der Unterseite der hohe Längskiel, an dessen Stelle verlängert sich ein breites, flaches, zungenförmiges Hornplättchen über den beiderseits gebogenen Vorderrand hinaus. Beim $\not$ ist der Ausschnitt des Pygidiums schmal und tief, das erste Hinterleibssegment ist längs der Mitte nicht kielartig erhöht. $3 \pi$ und 4 ㅇ․

5. Galerucella subcoerulescens: Ovalis, leviter convexa, sordide testacea, macula parva media prothoracis nigra, elytris brunneo-violaceis. Capite nitidulo, parce punctato, thorace lateribus rotundatis, disco parce punctato, nitido; elytris sat dense pubescentibus, subopacis, crebre punctatis, epipleuris ad angulum suturalem mucronatum continuatis. - Long. 4.5 mill.

Mas.: Segmento 5:o ventrali apice sat profunde triangulariter impresso.

Die Art verbindet ungefähr die Körperform der tenella mit der Punktirung der xanthomelaena; sie ist schmutzig gelbbraun, nur die Fld. (ohne das Schildchen) sind braun mit ziemlich starkem blauem Schimmer. Kopf, Halssch. und Unterseite sind sparsam, die Fld. dicht und fein weifslich behaart. Der Kopf ist mäfsig glänzend, weitläufig, wenig tief aber grob punktirt; Fühler nach der Spitze hin dunkel, Glied 3 kaum so lang als 4 . Halssch. überall glänzend, einzeln punktirt, die Mittellinie sehr schwach, mit einem länglichen schwarzen Punkte hinter der Mitte, oder noch 2 kleinen undeutlichen schwarzen Punkten davor; der Eindruck jederseits weit und tief; Seiten schwach gerundet-erweitert. Fld. wenig glänzend, dicht und ziemlich fein punktirt, die Punkte nicht nabelförmig, wie bei calmariensis L. und tenella. Die Epipleuren sind bis nahe zur Spitze gleich breit und fast bis zum Nahtwinkel deutlich, welcher in eine scharfe Spitze ausgezogen ist. Beine stark. Beim $\widetilde{\sigma}$ hat der 5. Bauchring eine tiefe, schmal-dreieckige Grube, die bis zur Hälfte des Ringes nach vorn reicht.

6. Cassida brevis: Breviter-ovalis, subconvexa, supra viridis, nitidissima, subtus nigra, femoribus apice, tibiis, tarsis limboque ventrali flavescentibus; thorace parce subtilissimeque punctato, subpolito, angulis posticis acutiusculis, elytris profunde fere regulariter punctato-striatis, interstitiis angustis, subcarinatis, sutura fere tota maculisque nonnullis disci sanguineis, margine fortiter explanato. - Long. 6 mill. 
Viel breiter, aber etwas weniger gewölbt, auf dem Halssch. glänzender, auf den Fld. stärker punktirt als die am nächsten stehende ornata Creutz. (azurea F.), fast kreisrund, nur die Seiten leicht parallel, oberseits bräunlichgrün, sehr stark glänzend, das Halssch. und die Zwischenräume der Fld. wie polirt. Kopf schwarz, matt, einzeln stark punktirt, die das Kopfschild begrenzenden Linien vereinigen sich in einem weiten Bogen vor der Fühlerwurzel. Fühler gelblich, die 5 letzten Glieder schwarz, Halssch. sehr kurz, fast dreimal so breit als lang, mit spitzwinkeligen Hinterecken. Fld. am Grunde so breit als das Halssch., dahinter wenig erweitert, hinten gemeinschaftlich breit abgerundet, mit 9 Punktstreifen. Davon sind die äufseren beiden regelmälsig, mit ebenem $\mathrm{Z}$ wischenraume, und bestehen aus dicht aneinander gedrängten feinen, überall gleich tiefen Punkten, die sieben inneren sind weitläufiger, aber viel stärker punktirt und erscheinen dadurch nicht ganz regelmäfsig, dafs sie einestheils durch zwei weite Vertiefungen der Fld. hindurchlaufen, anderntheils aber durch einige, zu kurzen Querfalten vereinigte Kanten, welche die Punkte trennen, verbunden werden; besonders tief sind die drei inneren Punktreihen an der Naht, ihre $Z_{\text {wischen- }}$ räume noch mehr gewölbt, als die äufseren. Die Seiten der Fld. sind sehr breit, flach ausgebreitet, grob runzelig punktirt, am äufsersten Rande aufgebogen. Blutroth gefärbt sind einige Makeln am Grunde und hinter dem Schildchen, der Nahtsaum und die drei ersten Punktstreifen. Unterseite schwarz, Spitze der Schenkel, die Schienen und Tarsen, sowie ein schmaler Saum des Bauches gelblich.

7. Coccinella lyncea var. asiatica: Prothorace macula albida triangulari, lateribus medium parum superante, maculis 6 elytrorum rubro-testaceis, macula basali et humeruli late confluentibus.

Makel 1 am Seitenrande unter dem Schulterhöcker ist hier mit Makel 2 an der Basis der Fld. stets zu einer einzigen, breiten, winkeligen Makel vereint. Während nun so an der Schulter ein Ueberflufs der hellen Färbung auftritt, zeigt das Halssch,, der Seitenrand und die Spitze der Fld. immer eine Abnahme derselben. Häufiger findet sich auch eine Form, bei welcher die Makeln 4 und 6 ganz fehlen; der Rand ist höchst selten hell.

Palästina (Abeille de Perrin), Amasia (Möhring), Scharud (Faust).

Cocc. Marmotıani Fairm. (Ann. Fr. 1868. 501) aus Marocco könnte zu dieser Varietät zu stellen sein. 


\section{$2 \mathrm{BHL}$ Biodiversity Heritage Library}

Weise, Julius. 1884. "Beitrag zur Chrysomeliden-Fauna von Amasia." Deutsche entomologische Zeitschrift 1884(2), 157-160.

https://doi.org/10.1002/mmnd.48018840206.

View This Item Online: https://www.biodiversitylibrary.org/item/103412

DOI: https://doi.org/10.1002/mmnd.48018840206

Permalink: https://www.biodiversitylibrary.org/partpdf/235299

\section{Holding Institution}

Harvard University, Museum of Comparative Zoology, Ernst Mayr Library

\section{Sponsored by}

Harvard University, Museum of Comparative Zoology, Ernst Mayr Library

\section{Copyright \& Reuse}

Copyright Status: Public domain. The BHL considers that this work is no longer under copyright protection.

This document was created from content at the Biodiversity Heritage Library, the world's largest open access digital library for biodiversity literature and archives. Visit BHL at https://www.biodiversitylibrary.org. 